\title{
Factors influencing the predation rates of Anisops breddini (Hemiptera: Notonectidae) feeding on mosquito larvae
}

\author{
R. Weterings, ${ }^{1,2}$ K.C. Vetter, ${ }^{3}$ C. Umponstira ${ }^{2}$ \\ ${ }^{1}$ Cat Drop Foundation, Drachten, The Netherlands; ${ }^{2}$ Department of Natural Resources and \\ Environment, Naresuan University, Thailand; ${ }^{3}$ Faculty of Ecology, University of Bremen, Germany
}

\begin{abstract}
Notonectidae are a family of water bugs that are known to be important predators of mosquito larvae and have great potential in the biological control of vector mosquitoes. An experiment was conducted to assess mosquito larvae predation by Anisops breddini, a species common to Southeast Asia. The predation rates were recorded in context of prey density, predator density, predator size and prey type. Predation rates were strongly affected by prey type and less by prey density and predator density. They ranged between 1.2 prey items per day for pupae of Aedes aegeypti and Armigeres moultoni to 5.9 for Ae. aegypti larvae. Compared with studies on other Notonectidae species, the predation
\end{abstract}

Correspondence: Robbie Weterings, Cat Drop Foundation, Boorn 45, 9204 AZ, Drachten, The Netherlands.

Tel.: +66.890176087.

E-mail: r.weterings@catdropfoundation.org

Key words: mosquito predation, Anisops breddini, biological control, predator density, prey density, prey type.

Contributions: RW data collecting and manuscript writing; KCV statistical analyses; CU study design and manuscript reviewing.

Conflict of interests: the authors declare no potential conflict of interests.

Funding: the work was mutually funded by a scholarship from the Faculty of Agriculture Natural Resources and Environment, Naresuan University and the Cat Drop Foundation.

Acknowledgements: the authors would like to thank the Faculty of Agriculture Natural Resources and Environment of Naresuan University and the Cat Drop Foundation for financial support. We would also like to thank Dr. Hannah L. Buckley for support, ideas and encouragement and Mr. Andrew Hunt for proof reading the manuscript.

Received for publication: 25 April 2014.

Revision received: 5 July 2014.

Accepted for publication: 9 July 2014.

CC Copyright R. Weterings et al., 2014

Licensee PAGEPress, Italy

Journal of Entomological and Acarological Research 2014; 46:4036

doi:10.4081/jear.2014.4036

This article is distributed under the terms of the Creative Commons Attribution Noncommercial License (by-nc 3.0) which permits any noncommercial use, distribution, and reproduction in any medium, provided the original author(s) and source are credited. rates appear low, which is probably caused by the relative small size of the specimens used in this study. An. breddini is very common in the region and often found in urban areas; therefore, the species has potential as a biological control agent.

\section{Introduction}

Mosquitoes are the world's number one arthropod vector of diseases such as malaria, dengue fever, filariasis or West Nile fever (Becker $e t$ $a l ., 2010)$. There are many predatory species that feed on mosquito larvae such as dragonfly naiads, aquatic beetles and fish (Shaalan \& Canyon, 2009). Notonectidae (Hemiptera) are a family of mosquito larvae predators that have often been the focus of biological control studies (Shaalan \& Canyon, 2009). These aquatic predators are commonly known as backswimmers (Gillot, 2005). Predation of mosquito larvae by backswimmer has been investigated throughout the world (Chesson, 1989; Martín \& López, 2004; Saha et al., 2007; Shaalan et al., 2007; Zuhara \& Lester, 2010; Silberbush \& Blaustein, 2011; Fischer et al., 2012). Many species of backswimmers are considered to have a strong feeding preference towards mosquito larvae.

Several studies have reported predation rates of backswimmers. Saha et al. (2007) showed that food deprived Anisops bouvieri fed on two to 34 mosquito larvae per day. Another study noted rates of eight to 30 mosquito larvae per day for Notonecta sellata (Fischer et al., 2012). In that study, 30 was the maximum number of mosquito larvae in each experimental trial, thus predation rates could possibly have been higher. Notonecta sellata fed on early mosquito instars at significantly higher rates than on late instars. A mean predation rate of 16 mosquito larvae per day was reported from Australia for an Anisops species (Shaalan et al., 2007). Here the predation rate for first instar mosquito larvae was 25 larvae per day, while fourth instars were preyed upon at rates of 13 larvae per day.

The current study provides insights into the mosquito predation rates of Anisops breddini, Kirkaldy 1901, a backswimmer species common to Southeast Asia. This species is often found in ponds and canals (Leong, 1962), but it was also frequently noticed in water storage tanks and other container-like ornaments. Water-filled containers are a major source of vector mosquitoes such as Aedes aegypti (Clements, 1999). Therefore, mosquito predators that inhabit these habitats are of particular interest for vector control. The effects of predator density, prey density and prey type on the predation rates were experimentally studied. It was hypothesized that with increasing predator densities the predation rates decrease. Interfering behaviour such as social behaviour is known to reduce predation rates (Beddington, 1975; Crowley \& Martin, 1989). In backswimmers, cannibalism is not uncommon and can cause a decrease in active hunting behaviour (Martín \& López, 2004). Prey density was expected to positively affect 
predation rates, subsequently showing a typical Holling type II functional response (Holling, 1959). The predation rates decelerate when the rates reach a food saturation point and handling time increases with lower prey densities (Holling, 1959; Giller, 1980; Gergs et al., 2010). Also, prey size and type are known to affect the predation rates of backswimmers (Murdoch et al., 1984; Chesson, 1989). A backswimmer needs to consume smaller prey to gain the same amount of energy in comparison with a larger prey (Gergs et al., 2010). Therefore predation rates were expected to differ among different prey types.

\section{Materials and methods}

An. breddini specimens were collected with a hand-held net in a temporary pond on October $22^{\text {nd, }} 2012$ in Kamphaeng Phet, Thailand (Latitude: $16^{\circ} 29^{\prime} 34.551$ ” N, Longitude: $99^{\circ} 30^{\prime} 53.0778$ " E). The specimens were kept in a bucket filled with water from the same pond. The specimens were collected one day prior to the experiment. Mosquito larvae were collected from a roof drain in the same area and from water storage containers in the nearby village, Nong Pling. The specimens were then identified using pictures taken with a digital microscope and the keys provided by Nieser (2004).

On the day prior to the experiment, An. breddini specimens were divided into 25 1.5-L transparent plastic containers, each filled with $1 \mathrm{~L}$ of water from the pond where the backswimmers were collected. This water was filtered to remove other aquatic organisms and debris. Backswimmers were then added to the containers in different densities ranging from one to five individuals per container. In total, there were five containers for every density treatment. However, a single backswimmer in one of the treatments with five backswimmers was found dead and was excluded from the study. A total of 70 backswimmers were used, which included both nymphs and adults with an average size of $3.7 \mathrm{~mm}(+/-0.13)$. The smallest specimen was $1.57 \mathrm{~mm}$ and the largest was $6.67 \mathrm{~mm}$. The mean body size for each predator density treatment is displayed in Table 1 . This study did not focus on adult specimens only, because this would inflate the predation rates. Natural populations consist of a mix of different age classes; therefore, a range of developmental stages was used that was representative for the habitat from which we collected the backswimmers (Table 2). A water plant (Pistia stratiotes L.) was also added to each of the containers to simulate a more natural habitat and to provide a substrate for the backswimmers and refuge for the mosquito larvae. The backswimmers were kept in their experimental habitat for one day to acclimatise.

The mosquito larvae were grouped per species (Ar. moultoni and Ae. aegypti) and were added to the containers in different densities, ranging from 5 to 30 mosquito larvae per container. Mosquitoes were added one day after the backswimmers were added, which marked the start of the experiment. Only $3^{\text {rd }}$ and $4^{\text {th }}$ instar mosquito larvae and pupae were used for this experiment. Prey treatments consisted of Ar. moultoni larvae, Ae. aegypti larvae or pupae of both species. Three containers were supplied with five prey items, five with ten prey items, five with 15 prey items, five with 20 prey items, four with 25 prey items, and two with 30 prey items. The mosquito larvae were added to the container in a way that maximized the number of unique treatment combinations (prey and predator densities), which increased the variation in the data. After $24 \mathrm{~h}$, the number of remaining mosquitoes were counted. This number was then subtracted from the starting density to estimate the number of mosquito larvae preyed upon. After the experimental trials, the backswimmers were placed onto a ruler and photographed. The photographs were analysed on the computer with Image J 1.46a software (Ferreira \& Rasband, 2012) to measure the length of every backswimmer.

Finally, the number of mosquitoes preyed upon were divided by the number of backswimmers in each container to gain an estimated predation rate (larvae/day/backswimmer). These predation rates were then analysed using linear regression models. A priori hypothesized models were developed following the model inference approach described by Anderson (2008). The predation rates were (log+1)-transformed to achieve normality. Nonlinear relationships were linearised using log transformations on the specific explanatory variables. All explanatory variables were standardised to a mean of zero and a standard deviation of one (Zuur et al., 2009). The Levene's test for equal variances was used to check for any violation of the assumption of equal variances among the different prey types.

The Akaike information criterion (AIC) scores were used to select the best model, the model with the lowest AICc score being the best model. AICc scores are similar to AIC scores but contain an extra penalty for additional variables; therefore, the AICc score is more conservative (Anderson, 2008). The model with the lowest AICc score was visualised using the visreg package (Breheny \& Burchett, 2012) in RStudio, version 0.97.551 (Rstudio, 2012), built on $\mathrm{R}$ version 3.0.2 ( $\mathrm{R}$ Development Core Team, 2013). Eventually, model selection probabilities were calculated to indicate the likeliness of a specific model to be the best model. These model probabilities were used to calculate an average model based on all the tested models (Anderson, 2008).

\section{Results}

The regression models displayed a typical non-linear functional response curve for predator density but not for prey density (Figure 1). Prey type was the most important variable in our models, followed by predator density and prey density, respectively (Table 3). The model with the lowest AICc score differed more than three points, which made calculation of an average model unnecessary (Table 4). This is reflected in the small differences of the parameter estimates between the best and averaged model (Table 3).

The log-transformed predation rates were significantly different for the three different prey types $(\mathrm{F}=6.14$, degree of freedom $=21$, $\mathrm{P}=0.008$ ). Tukey's post hoc test showed that the transformed predation rates were different for Ae. aegypti and pupae. There was no significant difference between Ar. moultoni and Ae. aegypti or Ar. moultoni and
Table 1. Mean size of $A n$. breddini for treatments with different predator densities.

\begin{tabular}{lc} 
Treatment & Mean predator sive $(\mathrm{mm})$ \\
1 predator & $3.8( \pm 0.6)$ \\
2 predators & $3.9( \pm 0.6)$ \\
\hline 3 predators & $3.9( \pm 0.3)$ \\
4 predators & $3.6( \pm 0.6)$ \\
\hline 5 predators & $3.5( \pm 0.5)$ \\
\hline
\end{tabular}

Table 2. Number of $A n$. breddini in different size classes.

\begin{tabular}{lc} 
Sire class $(\mathrm{mm})$ & Number of individuals \\
$0-2$ & 4 \\
$2.1-3$ & 15 \\
\hline $3.1-4$ & 20 \\
$4.1-5$ & 19 \\
\hline Greater than 5 & 7 \\
\hline
\end{tabular}


pupae. The mean ( \pm standard error) predation rate for Ae. aegypti was $5.94( \pm 0.79)$ mosquito larvae per day for Ar. moultoni, and for the pupae this was $3.78( \pm 2.2)$ and $1.23( \pm 0.42)$, respectively. The mean predator size was $3.71( \pm 0.14)$.

\section{Discussion}

The results of this study suggest that An. breddini feeds on a moderate number of mosquito larvae. The predation rates are highly dependent on the type of prey, the predator density and the prey density. Previous studies of other Notonectidae species have shown similar results. The predation rates were generally lower than that of other Notonectidae species. Saha et al. (2007) found predation rates between 2-32 mosquito larvae per day, with a mean of 15 for An. bouvieri. These predators, with a mean size of $6.22 \mathrm{~mm}$, were fed with Culex quinquifasciatus, a slightly smaller species than those from the genus Aedes (Saha et al., 2007). Moreover, their study did not include different predator densities (Saha et al., 2007). When considering only the treatment with a single predator and the smallest prey item, the mean predation rate was 8.7. Adult An. breddini and An. bouvieri are generally equal in size, with an approximate body length of 5.7-6.8 mm and 5.7-6.3 mm, respectively (Nieser, 2004). Nevertheless, the An. breddini specimens used in the current study were generally much smaller than An. bouvieri, which might explain the difference in predation rates. Predator
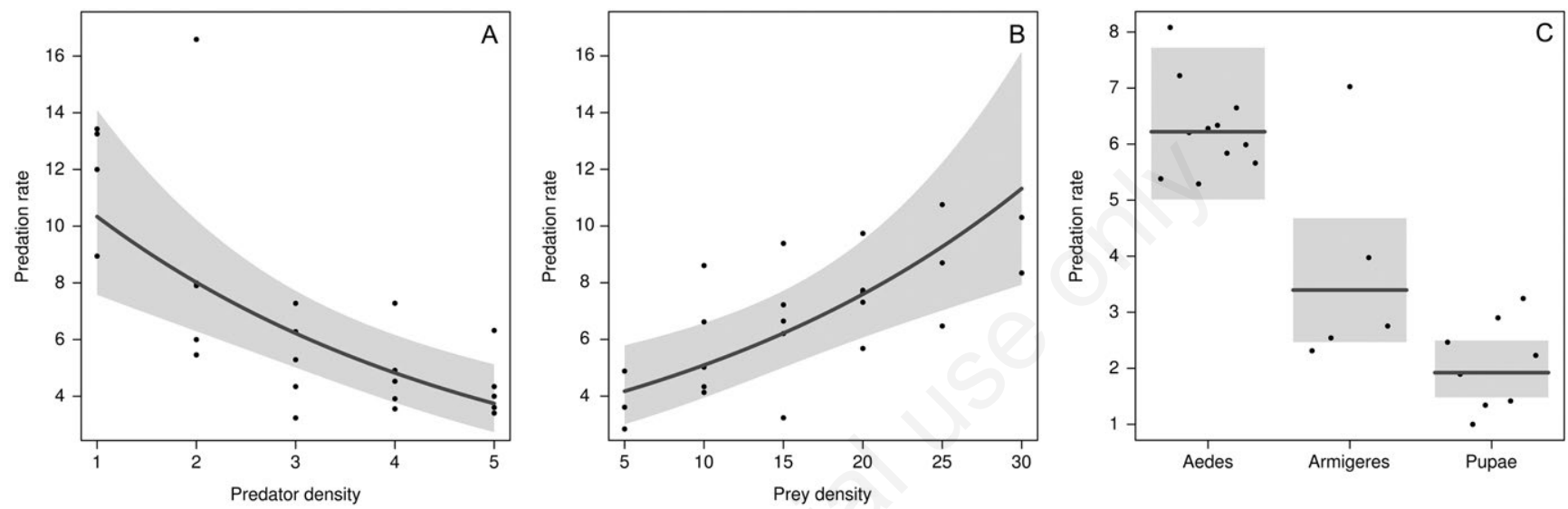

Figure 1. Visualisation of the best model based on back-transformed predation rates (Larvae per day). The grey areas display confidence bands. The dots in the graphs are kept constant for the variables that are not displayed in each specific graph. A) predator density versus predation rates, B) prey density versus predation rates and C) prey type versus predation rates.

Table 3. Model estimates of the best model and the averaged model for the regression models in which the predation rates were log+1 transformed.

\begin{tabular}{lcccc} 
& \multicolumn{2}{c}{ Best model } & \multicolumn{2}{c}{ Averaged model } \\
Model parameter & Estimate & Standard error & Estimate & 0.33 \\
log(prey density) & 0.33 & 0.07 & 0.38 & 0.07 \\
$\log$ (predator density) & 0.38 & 0.07 & 1.83 & 0.07 \\
\hline Type=Aedes & 1.83 & 0.09 & 0.43 & 0.09 \\
Type=Armigeres & 0.43 & 0.17 & 1.14 & 0.17 \\
\hline Type=pupae & 1.15 & 0.14 & 0.14 \\
\hline
\end{tabular}

Table 4. Comparison of all linear regression models.

\begin{tabular}{llcccc} 
Model* $^{*}$ & $\mathrm{~K}$ & $\Delta_{i}$ & & W $_{i}$ & Adjusted R $^{2}$ \\
$\mathrm{M}+\mathrm{P}+\mathrm{T}$ & 6 & 22.55 & 0.00 & 1.00 & 0.82 \\
$\mathrm{P}+\mathrm{T}$ & 5 & 36.75 & 14.20 & 0.00 & 0.64 \\
\hline $\mathrm{M}+\mathrm{T}$ & 5 & 41.75 & 19.20 & 0.00 & 0.55 \\
$\mathrm{~T}$ & 4 & 42.33 & 19.78 & 0.00 & 0.50 \\
\hline $\mathrm{M}+\mathrm{P}$ & 4 & 50.98 & 28.43 & 0.00 & 0.28 \\
$\mathrm{P}$ & 3 & 52.66 & 30.11 & 0.00 & 0.17 \\
$\mathrm{Null}$ & 2 & 55.63 & 33.08 & 0.00 & $\mathrm{NA}$ \\
$\mathrm{M}$ & 3 & 57.39 & 34.84 & 0.00 & -0.01 \\
\hline
\end{tabular}

*The variables for each model are given in the first column. M, prey density; P, predator density; T, prey type; K, number of parametes; AICc, Akaike information criterion; $\triangle_{i}$, difference in AICc score in comparison with the best model; $W_{i}$, the model weights. 
and prey size are important factors that strongly influence handling time and capture rates (Thompson, 1975; Hewett, 1980; Hirvonen \& Ranta, 1996). Fischer et al. (2012) also found higher predation rates for Notonecta sellata when feeding on Culex pipiens. They found a mean predation rate of 22 for $4^{\text {th }}$ instar mosquito larvae. These rates were slightly higher for $2^{\text {nd }}$ and $3^{\text {rd }}$ instar mosquito larvae (Fischer et al., 2012). Notonecta sellata is a relatively large species with a mean size of 8.7-9.6 mm (Heckman, 2011).

Predator densities strongly affected the predation rates of An. breddini. Predator density was also shown to affect predation rates in other studies on Notonectidae (Sih, 1981). In general, the mechanism behind this effect is that, with higher predator densities, the number of interactions between the predators increases (Sih, 1982; Crowley \& Martin, 1989). Also, cannibalism is more likely to occur with increased predator densities; this specifically affects predation rates of the smaller specimen when encountering larger conspecifics (Sih, 1982). Our data did not show a typical functional response curve for prey densities. We predicted that increased prey densities would positively affect predation rates in a decelerating manner until it reaches a maximum. This effect is often caused by satiation (Holling, 1959). If prey densities would have been further increased, this satiation level might have been reached, which also indicates that predation rates could potentially be higher with higher prey densities.

Predation rates differed significantly among different prey types. Predation rates were much higher for Ae. aegypti larvae in comparison to Ar. moultoni larvae or pupae. Although larval size was not measured, Ae. aegypti are generally smaller than Ar. moultoni larvae (Clements, 1999). Therefore, more prey items are needed to meet the same energy demands (Stephens \& Krebs, 1986). Prey size is an important driver in the predation rates of Notonectidae, which affects both the handling time as well as the capture rates (Murdoch et al., 1984). Several studies have investigated the prey preference of different Notonectidae species. When Notonectidae are exposed to different prey items, they generally show a preference for mosquito larvae over three species of water fleas (Cladocera) (Murdoch et al., 1984). Other studies, however, do not identify a preference for mosquito larvae (Chesson, 1989). Sih (1986) conducted an experiment on Notonecta undulata in which he compared the predation on Culex versus Aedes larvae. This study showed that the behaviour of the mosquito larvae was an important factor in prey selection. Aedes larvae generally did not display predator avoiding behaviour, while the Culex larvae did. As a result, Aedes larvae were preyed upon at much higher rates. This might partially explain the difference in predation rates, in particular the low predation rates for the pupae (pupae are generally less active). Nevertheless, in the current study, prey behaviour was not observed, nor were the predators exposed to different prey types simultaneously. Therefore, conclusions with regard to prey behaviour and predation rates cannot be drawn.

The current study showed that An. breddini feeds on only a small number of mosquito larvae compared to other backswimmer species (Saha et al., 2007; Fischer et al., 2012). These relative low predation rates can partly be ascribed to the use of mixed predator instars. Natural communities do not only consist of adult specimens, and these lower predation rates are therefore more realistic in comparison with predation rates based on adult specimens. In the current experiment, only third and fourth instar mosquito larvae were used. Early instar mosquito larvae are generally preyed upon in much higher rates than third and fourth instar mosquito larvae (Saha et al., 2007; Fischer et al., 2012). Predation rates are thus likely to be higher when An. breddini is exposed to first or second instar mosquito larvae.

An. breddini is very common in Thailand and other Southeast Asian countries (Leong, 1962), which is beneficial for the control of vector mosquitoes. Although other mosquito larvae predators might be more efficient in vector control, their wide distribution and abundance could potentially make An. breddini a valuable addition to existing biological vector control agents. Not only does An. breddini feed on mosquito larvae, there might also be other mechanisms that can benefit mosquito control. Other Notonectidae species are known to affect the development of mosquito larvae into adults (Fischer et al., 2012). In the presence of Notonectidae, development of mosquito larvae can take longer and adults tend to be smaller (Fischer et al., 2012). Other species are known to repel certain mosquito species from ovipositing (Blaustein $e t$ al., 2005; Silberbush \& Blaustein, 2011). More research is needed that focus on these last two aspects for An. breddini, which might reveal all the vector control benefits of this common species.

\section{References}

ANDERSON D.R., 2008 - Model based inference in the life sciences: a primer on evidence. - Springer, New York.

BECKER N., PETRIC D., ZGOMBA M., BOASE C., MADON M., DAHL C., KAISER A., 2010 - Mosquitoes and their control. - Springer, Berlin.

BEDDINGTON J.R., 1975 - Mutual interference between parasites or predators and its effect on searching efficiency - J. Anim. Ecol. 44: $331-340$.

BLAUSTEIN L., BLAUSTEIN J., CHASE J., 2005 - Chemical detection of the predator Notonecta irrorata by ovipositing Culex mosquitoes. J. Vector Ecol. 30: 299-301.

BREHENY P., BURCHETT W., 2012 - Visualization of regression models using Visreg. Page 10. - Lexington, Kentucky.

CHESSON J., 1989 - The effect of alternative prey on the functional response of Notonecta Hoffmani. - Ecology 70: 1227-1235.

CLEMENTS A.N., 1999 - The biology of mosquitoes. Volume 2: Sensory reception and behaviour. - CABI publishing, Wallingford.

CROWLEY P.H., MARTIN E.K., 1989 - Functional responses and interference within and between year classes of a dragonfly population. J. North Am. Benthol. Soc. 8: 211-221.

FERREIRA T., RASBAND W., 2012 - ImageJ user guide: IJ $1.46 \mathrm{r}$. Bethesda, MD.

FISCHER S., PEREYRA D., FERNÁNDEZ L., 2012 - Predation ability and non-consumptive effects of Notonecta sellata (Heteroptera: Notonectidae) on immature stages of Culex pipiens (Diptera: Culicidae). - J. Vector Ecol. 37: 245-251.

GERGS A., HOELTZENBEIN, N.I., RATTE H.T., 2010 - Diurnal and nocturnal functional response of juvenile Notonecta maculata considered as a consequence of shifting predation behaviour. - Behav. Processes 85: 151-6.

GILLER B.Y.P.S., 1980 - The control of handling time and its effects on the foraging strategy of a heteropteran predator, Notonecta. - J. Anim. Ecol. 49: 699-712.

GILLOT C., 2005 - Entomology. - Springer, Dordrecht.

HECKMAN C.W., 2011 - Encyclopedia of South American aquatic insects: Hemiptera - Heteroptera. - Springer, Dordrecht.

HEWETT S.W., 1980 - The effect of prey size on the functional and numerical responses of a protozoan predator to its prey. - Ecology 61: 1075-1081.

HIRVONEN H., RANTA E., 1996 - Prey to predator size ratio influences foraging efficiency of larval Aeshna juncea dragonflies. - Oecologia 106: 407-415.

HOLLING C.S., 1959 - Some characteristics of simple types of predation and parasitism. - Can. Entomol. 91: 385-398.

LEONG C.W., 1962 - The life-history of Anisops breddini Kirkaldy (Hemiptera, Notonectidae). - Annals Magazine Nat History 5: 377-383.

MARTÍN J., LÓPEZ P., 2004 - Balancing predation risk, social interference, and foraging opportunities in backswimmers, Notonecta maculata. - Acta Ethol. 6: 59-63. 
MURDOCH W.W., SCOTT M.A., EBSWORTH P., 1984 - Effects of the general predator, Notonecta (Hemiptera) upon a freshwater community. - J. Anim. Ecol.1 53: 791-808.

NIESER N., 2004 - Guide to aquatic Heteroptera of Singapore and Peninsular Malaysia III: Pleidae and Notonectidae. - Raffles Bull. Zool. 52: 79-96.

R DEVELOPMENT CORE TEAM, 2013 - R: A language and environment for statistical computing. - R Foundation for Statistical Computing, Vienna.

RSTUDI0, 2012 - RStudio: integrated development environment for R (Version 0n.96.331). - Boston, MA.

SAHA N., ADITYA G., BAL A., SAHA G.K., 2007 - A comparative study of predation of three aquatic heteropteran bugs on Culex quinquefasciatus larvae. - Limnology 8: 73-80.

SHAALAN E.A., CANYON D.V., 2009 - Review paper aquatic insect predators and mosquito control. - Trop. Biomed. 26: 223-261.

SHAALAN E.A., CANYON D.V., MULLER R., YOUNES M.W.F., ABDELWAHAB H., MANSOUR A.-H. 2007 - A mosquito predator survey in Townsville, Australia, and an assessment of Diplonychus sp. and Anisops sp. predatorial capacity against Culex annulirostris mosquito immatures. - J. Vector Ecol. 32: 16-21.
SIH A., 1981 - Stability, prey density and age/dependent interference in an aquatic insect predator, Notonecta hoffmanni. - J. Anim. Ecol. 50: 625-636.

SIH A., 1982 - Foraging strategies and the avoidance of predation by an aquatic insect, Notonecta Hoffmanni. - Ecology 63: 786-796.

SIH A., 1986 - Antipredator responses and the perception of danger by mosquito larvae. - Ecology 67: 434-441.

SILBERBUSH A., BLAUSTEIN L., 2011 - Mosquito females quantify risk of predation to their progeny when selecting an oviposition site. Funct. Ecol. 25: 1091-1095.

STEPHENS D.W., KREBS J.R., 1986 - Foraging theory. $1^{\text {st }}$ ed. - Princeton University Press, Princeton, NJ.

THOMPSON D.J., 1975 - Towards a predator-prey model incorporating age structure: the effects of predator and prey size on the predation of Daphnia magna by Ischnura elegans. - J. Anim. Ecol. 44: 907-916.

ZUHARAH W.F., LESTER P.J., 2010 - The influence of aquatic predators on mosquito abundance in animal drinking troughs in New Zealand. - J. Vector Ecol. 35: 347-353.

ZUUR A.F., IENO E.N., WALKER N., SAVELIEV A.A., SMITH G.M., 2009 Mixed effects models and extensions in ecology with R. - Springer, New York, NY. 